\title{
NMR Relaxation Dispersion Reveals Macrocycle Breathing Dynamics in a Cyclodextrin-based Rotaxane
}

\author{
Shannon Stoffel†, Qi-Wei Zhang§, Dong-Hao Li†, Bradley D. Smith†, Jeffrey W. Peng†, II,* \\ †Departments of Chemistry \& Biochemistry and IPhysics, University of Notre Dame, IN 46556, USA. §School of \\ Chemistry and Molecular Engineering, East China Normal University, Dongchuan Road 500, Shanghai 200241, \\ China \\ *E-mail: jpeng@nd.edu
}

\section{Supporting Information}

\section{Table of Contents}

Section A. Materials.......................................................................................................S2

Section B. NMR Spectroscopy.................................................................................S2

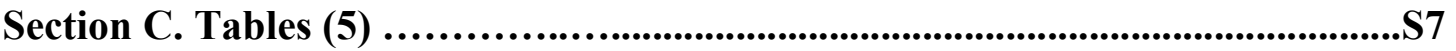

Section D. Figures (5) .........................................................................................S9

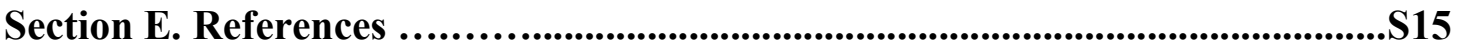




\section{A. Materials}

The two rotaxanes ([1]rotaxane pirouette-OFF, [3]rotaxane pirouette-ON) were synthesized as described by Zhang et al. ${ }^{1}$ The individual NMR samples were prepared by dissolving pre-weighed amounts of solid rotaxane in deuterated dimethyl sulfoxide (Dimethyl Sulfoxide-D6 D, 99.9\%, Cambridge Isotope Laboratories, Inc.) under airconditioned laboratory atmosphere conditions. The final sample concentrations were 4.3 $\mathrm{mM}$ for [3]rotaxane and $4.4 \mathrm{mM}$ for [1] rotaxane. The NMR samples were stored at $4^{\circ} \mathrm{C}$ in the dark and periodic evaluation of the samples by $700 \mathrm{MHz}{ }^{1} \mathrm{H}$ NMR showed no perceptible change in sample composition over the lifetime of the project.

\section{B. NMR Spectroscopy}

\section{General Aspects}

NMR spectra were recorded at $16.4 \mathrm{~T}\left(700 \mathrm{MHz}-{ }^{1} \mathrm{H}\right)$ on Bruker Avance I system, and at 18.8 T (800 MHz $\left.-{ }^{1} \mathrm{H}\right)$ on a Bruker Avance II system; both systems were equipped with TCI cryogenically-cooled probes. To ensure the same sample temperatures on these systems, we set the nominal temperature according to values established by a methanol temperature standard. ${ }^{2}$

The majority of NMR data were heteronuclear ${ }^{13} \mathrm{C}-{ }^{1} \mathrm{H} 2-\mathrm{D}$ spectra. All ${ }^{13} \mathrm{C}$ spectra were acquired at natural ${ }^{13} \mathrm{C}$ abundance $(\sim 1 \%)$. To optimize suppression of the ${ }^{12} \mathrm{C}$-bound protons, we used pulsed-field gradients for both coherence selection and signdiscrimination in the indirect dimension $\left(\mathrm{t}_{1},{ }^{13} \mathrm{C}\right)$. Time-domain data were Fourier transformed using TopSpin4.0.6 (Bruker Biospin, Inc.). Subsequent integration of 2-D cross-peaks, fits to decay functions, and exchange models were carried out using in-house software written in $\mathrm{C}$.

\section{Rotaxane ${ }^{1} \mathrm{H}$ and ${ }^{13} \mathrm{C}$ Resonance Assignments}

The ${ }^{1} \mathrm{H}$ and ${ }^{13} \mathrm{C}$ resonance assignments for [1] rotaxane (pirouette-OFF) were previously established by Zhang et al. ${ }^{1}$. By contrast, [3] rotaxane (pirouette- $\mathrm{ON}$ ) had only partial ${ }^{13} \mathrm{C}$ assignments. We completed the [3] rotaxane ${ }^{13} \mathrm{C}$ resonance assignments using standard 2-D ${ }^{1} \mathrm{H}-{ }^{1} \mathrm{H}$ DQF-COSY ${ }^{3}$, DIPSI-2 TOCSY (mixing time $72 \mathrm{~ms}$ ) ${ }^{4}$, ROESY (mixing time $72 \mathrm{~ms}$ ) ${ }^{5}$, and NOESY (mixing $60 \mathrm{~ms}$ ) .6,7 These were combined with 2-D heteronuclear sensitivity enhanced ${ }^{8,9}{ }^{1} \mathrm{H}-{ }^{13} \mathrm{C} \mathrm{HSQC}{ }^{10}$, and HSQC-TOCSY with sensitivity enhancement ${ }^{11}$ spectra, resulting in the assignments in Table $\mathbf{S 7}$ below. For chemical shift referencing, we used the solvent DMSO methyl ${ }^{1} \mathrm{H}$ (trace amounts) and ${ }^{13} \mathrm{C}$ resonances, $2.5 \mathrm{ppm}$ and $39.5 \mathrm{ppm}$, respectively. 12 


\section{Laboratory Frame ${ }^{13} \mathrm{C}$ Relaxation Rates}

We measured standard laboratory frame ${ }^{13} \mathrm{C}$ relaxation rate constants, $R_{1}=1 / T_{1}, R_{2}=1 / T_{2}$, and the steady-state heteronuclear ${ }^{13} \mathrm{C}-1 \mathrm{H}$ NOE to compare the overall rotational correlation times of the two rotaxanes.

${ }^{13} \mathrm{C} R_{1}=1 / T_{1}$ Measurements. To measure the ${ }^{13} \mathrm{C} \mathrm{R}_{1}$ values, we used standard 2-D ${ }^{1} \mathrm{H}-$ detected methods 13,14 , recording a series of 2-D spectra with different delay times for longitudinal ${ }^{13} \mathrm{C}$ relaxation. A train of ${ }^{1} \mathrm{H} 120^{\circ}$ pulses separated by $5 \mathrm{~ms}{ }^{15}$ was applied during the relaxation delay to saturate protons and minimize artifacts from CSA-DD crosscorrelated relaxation. ${ }^{16,17}$ Glucopyranose methine ${ }^{13} \mathrm{C} \mathrm{R}_{1}$ values were measured at $16.4 \mathrm{~T}$, $298 \mathrm{~K}$. The $2-\mathrm{D}$ datasets consisted of 1024 real points in $\mathrm{t}_{1}\left({ }^{1} \mathrm{H}, 15 \mathrm{ppm}\right.$ sweep width), 32 complex points in $\mathrm{t}_{1}\left({ }^{13} \mathrm{C}, 21 \mathrm{ppm}\right.$ sweep width), and 16 scans per $\mathrm{t}_{1}$ increment. We collected five 2-D spectra corresponding to $\mathrm{T}_{\text {RELAX }}=50(\mathrm{x} 2), 200,500$, and $750 \mathrm{~ms}$. The axle methylene ${ }^{13} \mathrm{C} \mathrm{R}_{1}$ spectra were recorded at both $16.4 \mathrm{~T}$ and $18.8 \mathrm{~T}$ at $298 \mathrm{~K}$. The 2 -D datasets consisted of 1024 real points in $\mathrm{t}_{2}\left({ }^{1} \mathrm{H}, 15 \mathrm{ppm}\right.$ sweep width), 64 complex points in $\mathrm{t}_{1}\left({ }^{13} \mathrm{C}\right.$, 38.4 ppm sweep width), with 48 scans per $t_{1}$ increment. The relaxation delays included $\mathrm{T}_{\text {RELAX }}=50(\mathrm{x} 2), 100,150,200,300,450,600,800$, and $1000 \mathrm{~ms}$.

${ }^{13} \mathrm{C} R_{2}=1 / T_{2}$ Measurements. The ${ }^{13} \mathrm{C} \mathrm{R}_{2}$ values were measured using standard 2-D CPMG methods with periodic proton inversion to minimize artifacts stemming from CSA-DD cross-correlated relaxation. ${ }^{16,18,19}$ We recorded a series of spectra with variable $\mathrm{T}_{\mathrm{RELAX}}$, and the interpulse delay $\mathrm{t}_{\mathrm{CP}}$ fixed at the smallest safe value (900 microseconds) with ${ }^{13} \mathrm{C}$ $180^{\circ}$ refocusing pulses at $6.67 \mathrm{kHz}$. Methine $\mathrm{R}_{2}$ values were measured at $16.4 \mathrm{~T}, 298 \mathrm{~K}$ with TRELAX values: $8.6(\mathrm{x} 2), 26,34,43,52(\mathrm{x} 2), 60,69,77,86$, and $94 \mathrm{~ms}$. The dataset sizes were 1024 real points in $t_{2}\left({ }^{1} \mathrm{H}, 15 \mathrm{ppm}\right.$ sweep width), 64 complex points in $\mathrm{t}_{1}\left({ }^{13} \mathrm{C}, 21 \mathrm{ppm}\right.$ sweep width), and 16 scans per $t_{1}$-increment. Methylene ${ }^{13} \mathrm{C}_{2}$ values were measured at both $16.4 \mathrm{~T}$ and $18.8 \mathrm{~T}$ at $298 \mathrm{~K}$. The dataset sizes were 1024 real points in $\mathrm{t}_{2}\left({ }^{1} \mathrm{H}, 15 \mathrm{ppm}\right.$ sweep width), 64 complex points in $\mathrm{t}_{1}\left({ }^{13} \mathrm{C}, 38.4 \mathrm{ppm}\right.$ sweep width), and 32 scans per $\mathrm{t}_{1}{ }^{-}$ increment. TRELAX values included 4.3 (x2), 8.6, 13, 24, 32, 34 (x2), 45, 56, 67, and 90 ms.

Extraction of $R_{1}$ and $R_{2}$. For both $\mathrm{R}_{1}$ and $\mathrm{R}_{2}$ spectra, the series of 2 -D cross-peaks were integrated with in-house software and fit to the two-parameter, single-exponential form, $\mathrm{I}\left(\mathrm{T}_{\mathrm{RELAX}}\right)=\mathrm{A} \bullet \exp \left\{-\mathrm{R}_{1, \text { or } 2} \bullet \mathrm{T}_{\mathrm{RELAX}}\right\}$, using the standard Levenburg-Marquardt algorithm ${ }^{20}$ for $\chi^{2}$ minimization. Spectral duplicates gave the peak intensity fluctuations used by Monte Carlo simulations to estimate the uncertainties in the fitted rate constants.

Steady-state heteronuclear ${ }^{1} \mathrm{H}-{ }^{13} \mathrm{C}$ NOEs. We measured steady-state ${ }^{1} \mathrm{H}-{ }^{13} \mathrm{C}$ for NOEs both rotaxanes at $16.4 \mathrm{~T}$ and 18.8T, $298 \mathrm{~K}$, using the Bruker pulse sequence "hsqcnoegpsi". The sequence records interleaved $2-\mathrm{D}{ }^{13} \mathrm{C}-1 \mathrm{H}$ spectra starting from ${ }^{13} \mathrm{C}$ polarization, in the presence versus absence of sustained ${ }^{1} \mathrm{H}$ saturation. The saturation duration was 3 secs and consisted of the same $120^{\circ}$ pulse train plus $5 \mathrm{~ms}$ delay used in the above $\mathrm{R}_{1}$ experiments. The 2-D datasets consisted of 1024 real points in $\mathrm{t}_{1}\left({ }^{1} \mathrm{H}, 15 \mathrm{ppm}\right.$ sweep width), 32 complex points in $t_{1}\left({ }^{13} \mathrm{C}, 21\right.$ ppm sweep width), and 128 scans per $t_{1}$ increment. We collected two saturation $\mathrm{ON}$ and two saturation $\mathrm{OFF}$ spectra. From these spectra, the steady-state NOE values were evaluated as $\left(\mathrm{I}_{\text {sat }}-\mathrm{I}_{\mathrm{eq}}\right) / \mathrm{I}_{\mathrm{eq}}$, where $\mathrm{I}_{\text {sat }}$ and $\mathrm{I}_{\mathrm{eq}}$ were the cross- 
peak intensities in the ${ }^{1} \mathrm{H}$ saturation $\mathrm{ON}$ versus OFF spectra, respectively. ${ }^{14}$ Statistical uncertainties were estimated via Monte Carlo simulations as described for $R_{1}$ and $R_{2}$.

\section{Transverse ${ }^{13} \mathrm{C}$ Relaxation Dispersion Measurements}

We recorded 2-D ${ }^{13} \mathrm{C}$ relaxation $\mathrm{CPMG}$ dispersion spectra for both rotaxanes at $16.4 \mathrm{~T}$. For the glucopyranose methine ${ }^{13} \mathrm{C}$ nuclei, we recorded dispersion spectra at three temperatures $(290,298$, and $303 \mathrm{~K})$ to estimate the activation energy. For the axle methylene carbons, we recorded dispersion spectra only at $298 \mathrm{~K}$.

We used standard 2-D ${ }^{13} \mathrm{C}-{ }^{1} \mathrm{H}$ pulse schemes containing a Carr-Purcell-Meiboom-Gill

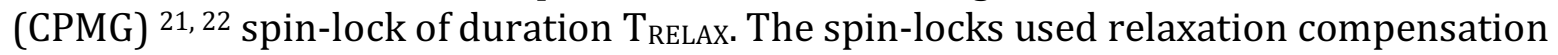
strategies appropriate for the methine ${ }^{23}$ and methylene spin systems. ${ }^{24}$ The ${ }^{13} \mathrm{C}$ hard pulses were applied at $17.24 \mathrm{kHz}$, while the ${ }^{13} \mathrm{C} 180^{\circ} \mathrm{CPMG}$ pulses were applied at lower power $(6.67 \mathrm{kHz})$. The CPMG rf-field strength was determined by the interpulse spacing, $\mathrm{t}_{\mathrm{CP}}$ via $v_{\mathrm{EFF}}=1 / 2 \mathrm{t}_{\mathrm{CP}} .{ }^{25,26}$ Each dispersion study consisted of a series of 2-D spectra with the same CPMG duration $\mathrm{T}_{\mathrm{RELAX}}=70 \mathrm{~ms}$, but variable $v_{\mathrm{EFF}}$ values that are listed below.

Methine Dispersion: For the glucopyranose methine ${ }^{13} \mathrm{C}$ nuclei, we used three carrier positions $(72.9,81.5$ and $101.5 \mathrm{ppm})$ to best achieve on-resonance conditions with the glucopyranose endocyclic methine carbons $\mathrm{C} 1, \mathrm{C} 2, \mathrm{C} 3, \mathrm{C} 4$. The vEFF values were: $28,58,88$, 118, 178, 208, 239(x2), 270, 333, 366, 398, 430, and 463 Hz. For each 2-D (i.e. each $v_{\mathrm{EFF}}$ value), we collected 160 FIDs corresponding to 80 complex points the ${ }^{13} \mathrm{C}_{1}$ dimension, covering a 32 ppm sweep width. Each FID was the co-addition of 16 scans and 1024 real data points in $\mathrm{t}_{2}\left({ }^{1} \mathrm{H}, 12 \mathrm{ppm}\right.$ sweep width).

Methylene Dispersion. For the axle methylene ${ }^{13} \mathrm{C}$ nuclei, one carrier position (28 ppm) sufficed. We collected 2-D spectra to sample $v_{\text {EFF }}$ values, 43, 86 (x2), 130, 175, 220, 265, $312,359,407$, and $455 \mathrm{~Hz}$. For each 2-D, we collected 96 FIDs with 16 scans each. Each 2-D dataset consisted of 1024 real data points in $t_{2}\left({ }^{1} \mathrm{H}, 11 \mathrm{ppm}\right.$ sweep width), 96 real points (48 time points) in $\mathrm{t}_{1}\left({ }^{13} \mathrm{C}, 36.4 \mathrm{ppm}\right.$ sweep width).

Extraction of $R_{2, E F F}$ versus $v_{\mathrm{EFF}}$. We used the same procedure to extract the $\mathrm{R}_{2, \mathrm{EFF}}$ values from the methine and methylene 2-D ${ }^{13} \mathrm{C}-{ }^{1} \mathrm{H}$ spectra. Post Fourier transformation, we integrated the $2-D^{13} \mathrm{C}-{ }^{1} \mathrm{H}$ cross-peaks using in-house software, getting $\mathrm{I}\left(v_{\mathrm{EFF}}\right)$ versus $v_{\mathrm{EFF}}=\left(1 / 2 \mathrm{t}_{\mathrm{CP}}\right)$ data files for each resolved cross-peak. We then generated $R_{2, E F F}$ versus $v_{\text {EFF }}$ profiles using the relation

$$
\mathrm{R}_{2, \mathrm{EFF}}\left(\nu_{\mathrm{EFF}}\right)=-1 / \mathrm{T}_{\mathrm{RELAX}}{ }^{*} \ln \left\{\mathrm{I}\left(\nu_{\mathrm{EFF}}\right) / \mathrm{I}_{\mathrm{REF}}\right\}
$$

,${ }^{27}$ where I $\left(v_{\mathrm{EFF}}\right)$ and $\mathrm{I}_{\mathrm{REF}}$ are the cross-peak intensities in the presence and absence of the CPMG spin-lock, respectively. Uncertainties in the rate constants were estimated by Monte Carlo simulations of peak intensities, based on spectral duplicates.

Extraction of two-state exchange parameters. The CPMG $\mathrm{R}_{2 \mathrm{eff}}$ versus $\mathrm{v}_{\mathrm{EFF}}$ profiles were fit to a two-state exchange model $(\mathrm{A} \leftarrow \rightarrow \mathrm{B})$, using the expressions from Carver and Richards. ${ }^{28}$ These expressions are valid across all time scales of two-state exchange. We used Carver- 
Richards expressions that assume a negligible difference between the intrinsic relaxation rate constants for the two exchanging states (Eqs S2, S3, S4, and S5):

$$
\begin{gathered}
R_{2, E F F}\left(v_{E F F}\right)=R_{2, N E}(0)+\frac{k_{e x}}{2}-\frac{1}{2 t_{c p}} \operatorname{Cosh}^{-1}\left(D_{+} \cosh \Gamma_{+}-D_{-} \cos \Gamma_{-}\right) \\
D_{ \pm}=\frac{1}{2}\left\{ \pm 1+\frac{\psi+2(\delta \omega)^{2}}{\sqrt{\psi^{2}+\zeta^{2}}}\right\}, \Gamma_{ \pm}=\frac{t_{c p}}{\sqrt{2}} \sqrt{\left\{ \pm \psi+\sqrt{\psi^{2}+\zeta^{2}}\right\}}(\mathrm{S} 3) \\
\psi=\left(\left(1-P_{\text {min }}\right) k_{e x}+P_{\text {min }} k_{e x}\right)^{2}-(\Delta \omega)^{2}+4\left(1-P_{\text {min }}\right) P_{\text {min }} k_{e x}{ }^{2} \\
\zeta=2(\Delta \omega)\left(\left(1-P_{\text {min }}\right) k_{e x}+P_{\text {min }} k_{e x}\right)^{2}(\mathrm{~S} 5)
\end{gathered}
$$

The above Carver-Richards expressions (Eqs S2-5) contain four adjustable parameters: the net exchange rate constant, $\mathrm{k}_{\mathrm{ex}}=\mathrm{k}(\mathrm{A}->\mathrm{B})+\mathrm{k}(\mathrm{B}->\mathrm{A})$; the fractional population of the minor species, $P_{\text {min }}$; the chemical shift difference between the two putative states, $\Delta_{\mathrm{ppm}}$; and $\mathrm{R}_{2, \mathrm{NE}}$, the nominal non-exchange contributions to $\mathrm{R}_{2, \mathrm{EFF}}$, including relaxation from dipole-dipole interactions and anisotropic chemical shielding. We searched for optimal fitting parameters by minimizing the $\chi^{2}$ error using a grid-search algorithm. ${ }^{29}$ For global fits, we kept $\mathrm{k}_{\mathrm{ex}}$ and $\mathrm{P}_{\min }$ the same for all ${ }^{13} \mathrm{C}$ nuclei, while letting $\Delta_{\mathrm{ppm}}$ and $\mathrm{R}_{2, \mathrm{NE}}$ vary for each site. Uncertainties in the fitted parameters were estimated by jack-knife simulations.

\section{${ }^{1} H_{1} R_{1 \rho}$ Dispersion Measurements}

${ }^{1} \mathrm{H} \mathrm{R}_{1 \rho}=1 / \mathrm{T}_{1 \rho}$ dispersion profiles for hydroxyl protons at $5.86 \mathrm{ppm}$ were recorded at $16.4 \mathrm{~T}$, at three temperatures $(290,298$, and $303 \mathrm{~K})$. The $\mathrm{R}_{1 \rho}$ spin-lock was a simple continuous-wave spin-lock with duration $\mathrm{T}_{\mathrm{LOCK}}{ }^{30,31}$, bracketed by delays to compensate for off-resonance effects. ${ }^{32}$ To simplify the spectra, we used selective excitation of the hydroxyl region using the e-PHOGSY spin-echo ${ }^{33}$ consisting of a 2.5 ms Reburp ${ }^{34}$ pulse applied at $5.86 \mathrm{ppm}$ (peak power applied at $19.8 \mathrm{~dB}$ attenuation relative to that used for hard ${ }^{1} \mathrm{H}$ pulses) between delays of $5.6 \mathrm{~ms}$. The $\mathrm{R}_{1 \rho}$ dispersion measurements meant determining $\mathrm{R}_{1 \rho}$ as function of the ${ }^{1} \mathrm{H}$ spin-lock rf-field strength, $v_{S L}$. For a given $v_{S L}$, we monitored the residual ${ }^{1} \mathrm{H}$ magnetization after spin lock durations including: $5(\mathrm{x} 2), 10,15$, $20,30,40(\mathrm{x} 2), 50,70$, and $80 \mathrm{~ms}$, storing the results in a pseudo 2-D dataset. The procedure was repeated for other $v_{S L}$ values, thus determining $R_{1 \rho}$ at $v_{S L}=500,600,800$, $1000,1750,2500,3000$, and $5000(x 2) \mathrm{Hz}$. We fit the $\mathrm{R}_{1 \rho}$ versus vSL data to the TrottPalmer two-state exchange model in Eq S6 ${ }^{35}$,

$$
R_{1 \rho}\left(v_{S L}\right)=R_{1 \rho, N E}+\frac{P_{\min }\left(1-P_{\min }\right)(\delta \omega)^{2}}{k_{e x}{ }^{2}+(\delta \omega)^{2}+\left(2 \pi v_{S L}\right)^{2}}
$$

The above Trott-Palmer expression contains four adjustable parameters: the net exchange rate constant, $k_{\mathrm{ex}}=\mathrm{k}(\mathrm{A}->\mathrm{B})+\mathrm{k}(\mathrm{B}->\mathrm{A})$, the fractional population of the minor species, $\mathrm{P}_{\min }$; the chemical shift difference between the two states, $\Delta_{\mathrm{ppm}}$; and $R_{1 \rho, \mathrm{NE}}$ the nominal nonexchange contributions to $\mathrm{R}_{1 \rho}$. 
For both the ${ }^{13} \mathrm{C}$ and ${ }^{1} \mathrm{H}$ dispersion data, we searched for optimal model parameter values by minimizing the residual $\chi^{2}$ error using a grid-search algorithm. ${ }^{29}$ For global fits, we stepped $\mathrm{k}_{\mathrm{ex}}$ and $\mathrm{P}_{\min }$ through a range of values comprising a two-dimensional grid, each grid point being a particular ordered pair of $k_{e x}$ and $P_{\min }$. At each grid point, we kept $k_{e x}$ and $\mathrm{P}_{\min }$ fixed while letting the $\Delta_{\mathrm{ppm}}$ and $\mathrm{R}_{2, \mathrm{NE}}$ parameters vary site-specifically. The optimal parameters were taken from the grid point yielding the lowest $\chi^{2}$ error. Uncertainties in the site-specific fitted parameters were estimated by jack-knife simulations. Uncertainties in the stepped global parameters were estimated by finding the range of $\mathrm{k}_{\mathrm{ex}}$ and $\mathrm{P}_{\min }$ values producing a $1 \%$ increase in $\chi^{2}$ from its minimal value.

The $\mathrm{k}_{\mathrm{ex}}$ and $\mathrm{P}_{\min }$ values from the ${ }^{13} \mathrm{C} \mathrm{CPMG}$ and ${ }^{1} \mathrm{H} \mathrm{R}_{1 \rho}$ dispersion data showed similar trends with increasing temperature. At $290 \mathrm{~K}$ and $298 \mathrm{~K}$, the ${ }^{13} \mathrm{C} C \mathrm{CPMG}$ and ${ }^{1} \mathrm{H} \mathrm{R}_{1 \rho}$ global fitting parameters, $\mathrm{k}_{\mathrm{ex}}$ and $\mathrm{P}_{\min }$ were within the estimated uncertainties of each other.

\section{Diffusion-Ordered Spectroscopy}

A pseudo 2-D Diffusion-Ordered Spectroscopy (DOSY) sequence was used to measure the translational diffusion coefficient. ${ }^{36}$ The Bruker pulse program, "stebpsp1s", with parameters $\Delta=60 \mathrm{~ms}, \delta=800 \mu \mathrm{s}$, and a linear gradient $2-80 \%$ in 64 incremental steps. The DOSY spectra were processed using local covariance order DOSY (LOCODOSY) ${ }^{37}$ part of the DOSY Toolbox package. ${ }^{38}$ Best value estimates and statistical errors were provided by the DOSY Toolbox package. Example of the spectra are shown in Supporting Information Figure S2. 


\section{Supporting Information Tables}

Table S1. [3] rotaxane (pirouette-ON) Relaxation: 16.4T, d6-DMSO, 4.3mM, T=298K

\begin{tabular}{|c|c|c|c|}
\hline Site $^{\mathrm{a}}$ & $\mathrm{R}_{\mathrm{c}}\left(\mathrm{C}_{\mathrm{Z}}\right)$ & $\mathrm{R}_{\mathrm{c}}\left(\mathrm{C}_{\mathrm{X}, \mathrm{Y}}\right)$ & $\mathrm{NOE}(\eta)^{\mathrm{b}}$ \\
\hline $\mathrm{CH}-1$ & $1.93 \pm 0.01$ & $14.35 \pm 0.03$ & $0.144 \pm 0.005$ \\
\hline $\mathrm{CH}-2$ & $1.94 \pm 0.01$ & $18.90 \pm 0.05$ & $0.156 \pm 0.001$ \\
\hline $\mathrm{CH}-3$ & $1.89 \pm 0.01$ & $12.93 \pm 0.03$ & $0.164 \pm 0.001$ \\
\hline $\mathrm{CH}-4$ & $2.03 \pm 0.01$ & $14.74 \pm 0.12$ & $0.144 \pm 0.003$ \\
\hline $\mathrm{CH}-5$ & $1.96 \pm 0.01$ & $13.13 \pm 0.07$ & $0.159 \pm 0.002$ \\
\hline${ }^{*} \mathrm{CH}_{2}-6$ & $3.53 \pm 0.01$ & $13.40 \pm 0.39$ & $0.144 \pm 0.018$ \\
\hline $\mathrm{CH}_{2}-6$ & $3.57 \pm 0.01$ & $11.08 \pm 0.67$ & $0.127 \pm 0.057$ \\
\hline $\mathrm{CH}_{2}-\mathrm{g}$ & $2.36 \pm 0.01$ & $10.23 \pm 0.44$ & $0.549 \pm 0.048$ \\
\hline
\end{tabular}

aStars indicate the downfield shift of the methylene group ${ }^{b} \mathrm{NOE}$ data are reported as $\eta=[I(s a t)-I(e q)] / I(e q)$.

Table S2. [1]rotaxane (pirouette-OFF) Relaxation: 16.4T, d6-DMSO, 4.6mM, T=298K

\begin{tabular}{|c|l|l|l|}
\hline Site $^{\mathrm{a}, \mathrm{c}, \mathrm{d}}$ & $\mathrm{R}_{\mathrm{c}}\left(\mathrm{C}_{\mathrm{Z}}\right)$ & $\mathrm{R}_{\mathrm{c}}\left(\mathrm{C}_{\mathrm{X}, \mathrm{Y}}\right)$ & $\mathrm{NOE}(\eta)^{\mathrm{b}}$ \\
\hline $\mathrm{A} \mathrm{CH}-1$ & $1.97 \pm 0.02$ & $13.92 \pm 0.05$ & $0.138 \pm 0.014$ \\
\hline $\mathrm{B} \mathrm{CH}-1$ & $1.94 \pm 0.06$ & $13.79 \pm 0.02$ & $0.146 \pm 0.008$ \\
\hline $\mathrm{E} \mathrm{CH}-1$ & $1.94 \pm 0.04$ & $13.74 \pm 0.35$ & $0.137 \pm 0.012$ \\
\hline $\mathrm{F} \mathrm{CH}-1$ & $1.96 \pm 0.01$ & $13.45 \pm 0.16$ & $0.136 \pm 0.018$ \\
\hline $\mathrm{A} \mathrm{CH}-2$ & $2.00 \pm 0.01$ & $13.37 \pm 0.20$ & $0.127 \pm 0.003$ \\
\hline $\mathrm{A} \mathrm{CH}-3$ & $1.90 \pm 0.02$ & $13.46 \pm 0.03$ & $0.146 \pm 0.005$ \\
\hline $\mathrm{A} \mathrm{CH}-4$ & $1.99 \pm 0.07$ & $13.58 \pm 0.01$ & $0.136 \pm 0.018$ \\
\hline $\mathrm{F} \mathrm{CH}-4$ & $2.12 \pm 0.01$ & $13.36 \pm 0.68$ & $0.137 \pm 0.005$ \\
\hline $\mathrm{A} \mathrm{CH}-5$ & $2.01 \pm 0.05$ & $13.34 \pm 0.07$ & $0.125 \pm 0.002$ \\
\hline B CH-5 & $2.04 \pm 0.07$ & $13.74 \pm 0.41$ & $0.141 \pm 0.011$ \\
\hline${ }^{*} \mathrm{~A} \mathrm{CH}_{2}-6$ & $3.93 \pm 0.36$ & $16.56 \pm 0.23$ & $0.118 \pm 0.045$ \\
\hline $\mathrm{A} \mathrm{CH}_{2}-6$ & $4.13 \pm 0.13$ & $16.43 \pm 0.76$ & $0.112 \pm 0.035$ \\
\hline${ }^{*} \mathrm{~B} \mathrm{CH}_{2}-6$ & $4.08 \pm 0.11$ & $13.75 \pm 0.51$ & $0.149 \pm 0.045$ \\
\hline B CH$_{2}-6$ & $3.75 \pm 0.42$ & $13.61 \pm 0.67$ & $0.128 \pm 0.029$ \\
\hline${ }^{*} \mathrm{~g} \mathrm{CH}_{2}-6$ & $2.74 \pm 0.24$ & $11.31 \pm 0.33$ & $0.461 \pm 0.046$ \\
\hline g CH$_{2}-6$ & $2.86 \pm 0.05$ & $10.34 \pm 0.26$ & $0.449 \pm 0.011$ \\
\hline
\end{tabular}

aStars indicate the downfield shift of the methylene group

${ }^{\mathrm{b}} \mathrm{NOE}$ data are reported as $\eta=[I(s a t)-I(e q)] / I(e q)$.

${ }^{\mathrm{c}}$ Methylene carbon relaxation recorded at $4.4 \mathrm{mM}$ concentration 
Table S3. [1] rotaxane (pirouette-OFF) Relaxation: 18.8T, d6-DMSO, 4.6mM, T=298K

\begin{tabular}{|c|c|c|}
\hline Site & $\mathrm{R}_{\mathrm{c}}\left(\mathrm{C}_{\mathrm{z}}\right)$ & $\mathrm{NOE}(\eta)^{\mathrm{b}}$ \\
\hline${ }^{*} \mathrm{~A} \mathrm{CH}_{2}-6$ & $3.20 \pm 0.08$ & $0.102 \pm 0.031$ \\
\hline $\mathrm{A} \mathrm{CH}_{2}-6$ & $3.12 \pm 0.09$ & $0.037 \pm 0.026$ \\
\hline $\mathrm{B} \mathrm{CH}_{2}-6$ & $3.00 \pm 0.09$ & $0.067 \pm 0.031$ \\
\hline${ }^{*} \mathrm{~B} \mathrm{CH}_{2}-6$ & $3.00 \pm 0.09$ & $0.062 \pm 0.034$ \\
\hline $\mathrm{CH}_{2}-\mathrm{g}$ & $2.65 \pm 0.95$ & $0.309 \pm 0.039$ \\
\hline${ }^{*} \mathrm{CH}_{2}-\mathrm{g}$ & $2.60 \pm 0.96$ & $0.297 \pm 0.025$ \\
\hline
\end{tabular}

aStars indicate the downfield shift of the methylene group

$\mathrm{b}_{\mathrm{NOE}}$ data reported as $\eta=[I(s a t)-I(e q)] / I(e q)$.

Table S4. [3] rotaxane (pirouette-ON) Relaxation: 18.8T, d6-DMSO, 4.3mM, T=298K

\begin{tabular}{|c|c|c|}
\hline Site $^{\mathrm{a}}$ & $\mathrm{Rc}\left(\mathrm{C}_{\mathrm{z}}\right)$ & $\mathrm{NOE}(\eta)^{\mathrm{b}}$ \\
\hline $\mathrm{CH}_{2}-6^{*}$ & $2.88 \pm 0.19$ & $0.095 \pm 0.028$ \\
\hline $\mathrm{CH}_{2}-6$ & $2.91 \pm 0.17$ & $0.100 \pm 0.012$ \\
\hline $\mathrm{CH}_{2}-\mathrm{g}$ & $2.09 \pm 0.19$ & $0.415 \pm 0.017$ \\
\hline
\end{tabular}

aStars indicate the downfield shift of the methylene group

${ }^{\mathrm{b}} \mathrm{NOE}$ data reported as $\eta=[I(s a t)-I(e q)] / I(e q)$.

Table S5. [3]rotaxane (pirouette-ON) ${ }^{13} \mathrm{C}$ Resonance Assignments 16.4T, d6-DMSO, $4.3 \mathrm{mM}, \mathrm{T}=298 \mathrm{~K}$

\begin{tabular}{|c|c|c|c|}
\hline \multicolumn{2}{|c|}{ substructural unit } & $\delta_{\mathrm{H}}(\mathrm{ppm})$ & $\delta_{\mathrm{C}}(\mathrm{ppm})$ \\
\hline \multirow[t]{9}{*}{ cyclodextrin } & $\mathrm{CH}-1$ & 4.776 & 101.625 \\
\hline & $\mathrm{CH}-2$ & 3.239 & 72.317 \\
\hline & $\mathrm{OH}-2$ & 5.619 & \\
\hline & $\mathrm{CH}-3$ & 3.811 & 73.357 \\
\hline & $\mathrm{OH}-3$ & 5.559 & \\
\hline & $\mathrm{CH}-4$ & 3.481 & 80.898 \\
\hline & $\mathrm{CH}-5$ & 3.767 & 71.190 \\
\hline & $\mathrm{CH}_{2}-6$ & $3.489,3.708$ & 58.883 \\
\hline & $\mathrm{OH}-6$ & 4.187 & \\
\hline & $\mathrm{CH}-\mathrm{f}$ & 8.349 & 149.883 \\
\hline & CH-e & 7.572 & 122.946 \\
\hline & CH-d & 6.994 & 124.588 \\
\hline & $\mathrm{CH}-\mathrm{C}$ & 7.082 & 126.762 \\
\hline & CH-b & 7.426 & 131.910 \\
\hline & $\mathrm{CH}_{2}-\mathrm{g}$ & 3.950 & 73.963 \\
\hline & $\mathrm{CH}_{2}-\mathrm{h}$ & 1.745 & 28.112 \\
\hline & $\mathrm{CH}_{2}-\mathrm{i}$ & 1.345 & 25.774 \\
\hline & $\mathrm{CH}_{2}-\mathrm{j}$ & 1.345 & 25.774 \\
\hline & $\mathrm{CH}_{2}-\mathrm{k}$ & 1.408 & 29.761 \\
\hline & $\mathrm{CH}_{2}-\mathrm{I}$ & 1.408 & 29.761 \\
\hline
\end{tabular}


D. Supporting Information Figures 

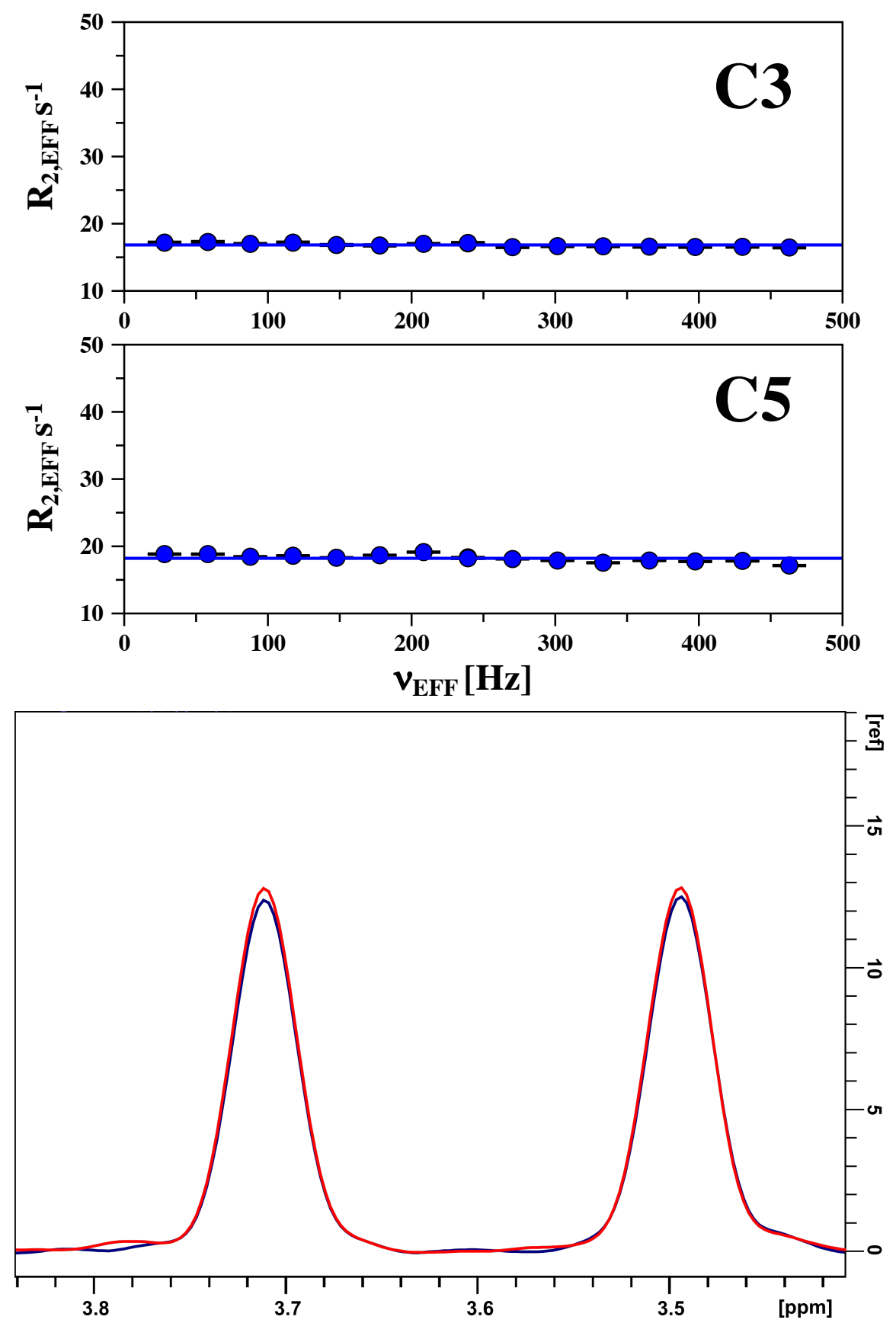

Figure S1. (Top) ${ }^{13} \mathrm{C}$ natural abundance CPMG R2,EFF versus $v_{\text {EFF }}(28$ to $463 \mathrm{~Hz})$ for $\alpha \mathrm{CD}$ glucopyranose carbons C3(top) and C5 (bottom) for [3] rotaxane (16.4T, $\mathrm{T}=290 \mathrm{~K}, \mathrm{DMSO}-\mathrm{d} 6$ ). The flat dispersion profile denotes an absence of exchange detected at these glucopyranose sites. Spectral parameters are described above in the NMR Spectroscopy section of the methods section above. (Bottom) Overlay of glucopyranose site C6 of [3] rotaxane (16.4T, DMSO, 290K) at a $v_{\mathrm{EFF}}$ of $28 \mathrm{~Hz}$ (Blue trace) and $463 \mathrm{~Hz}$ (Red trace). There is a minimal change in intensity with increasing $v_{\mathrm{EFF}}$, indicating an absence of detectable exchange. 


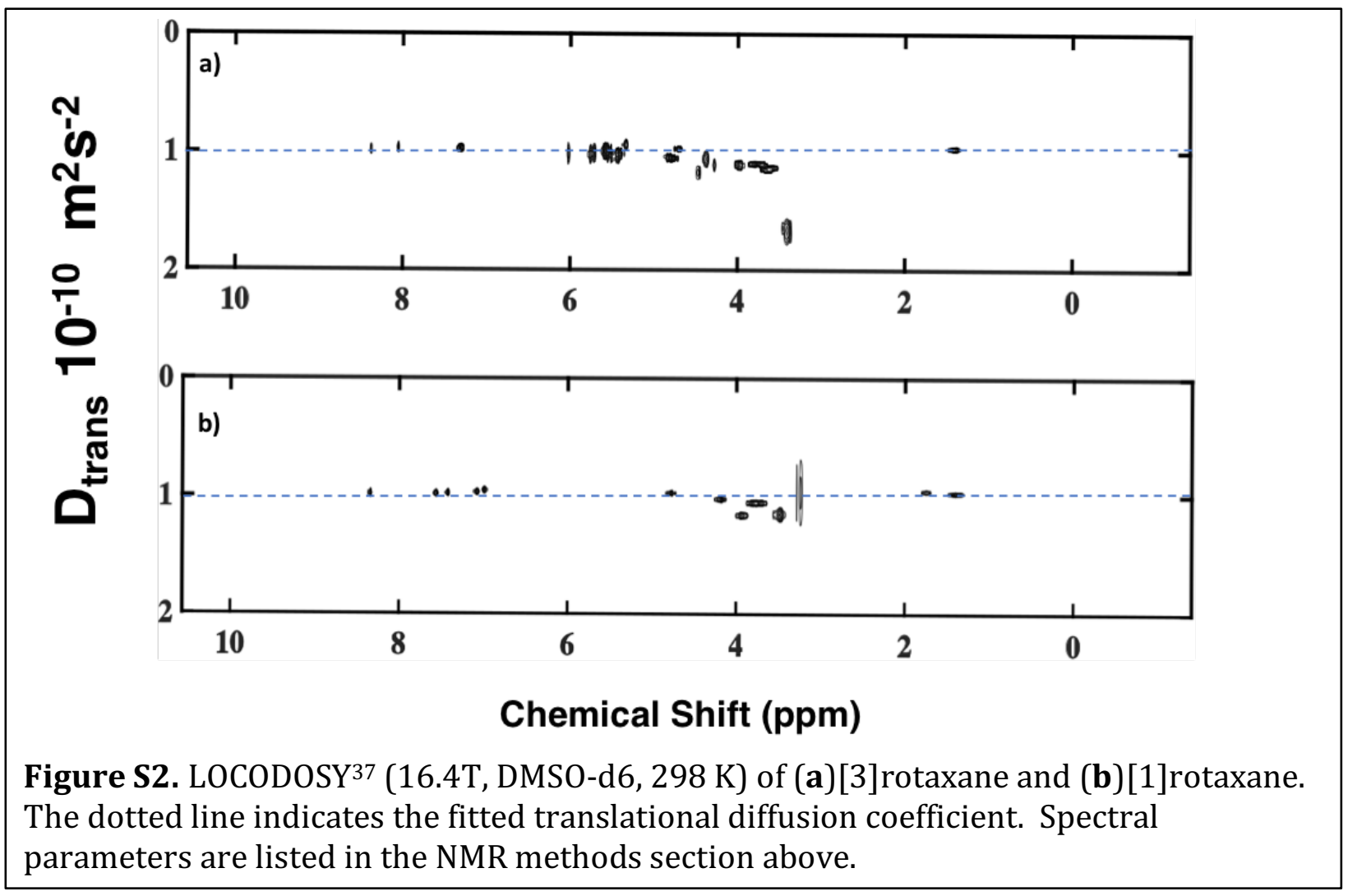




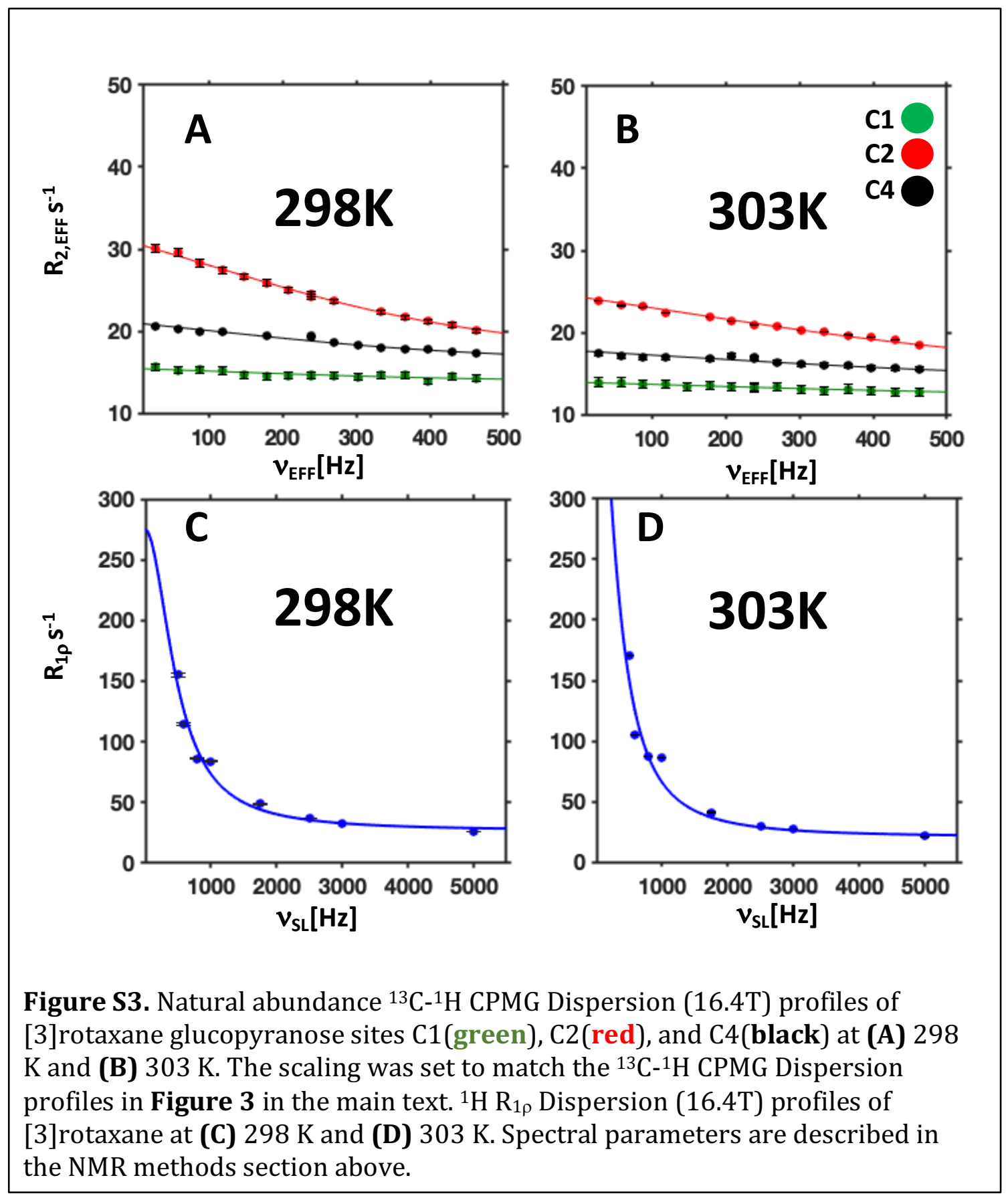




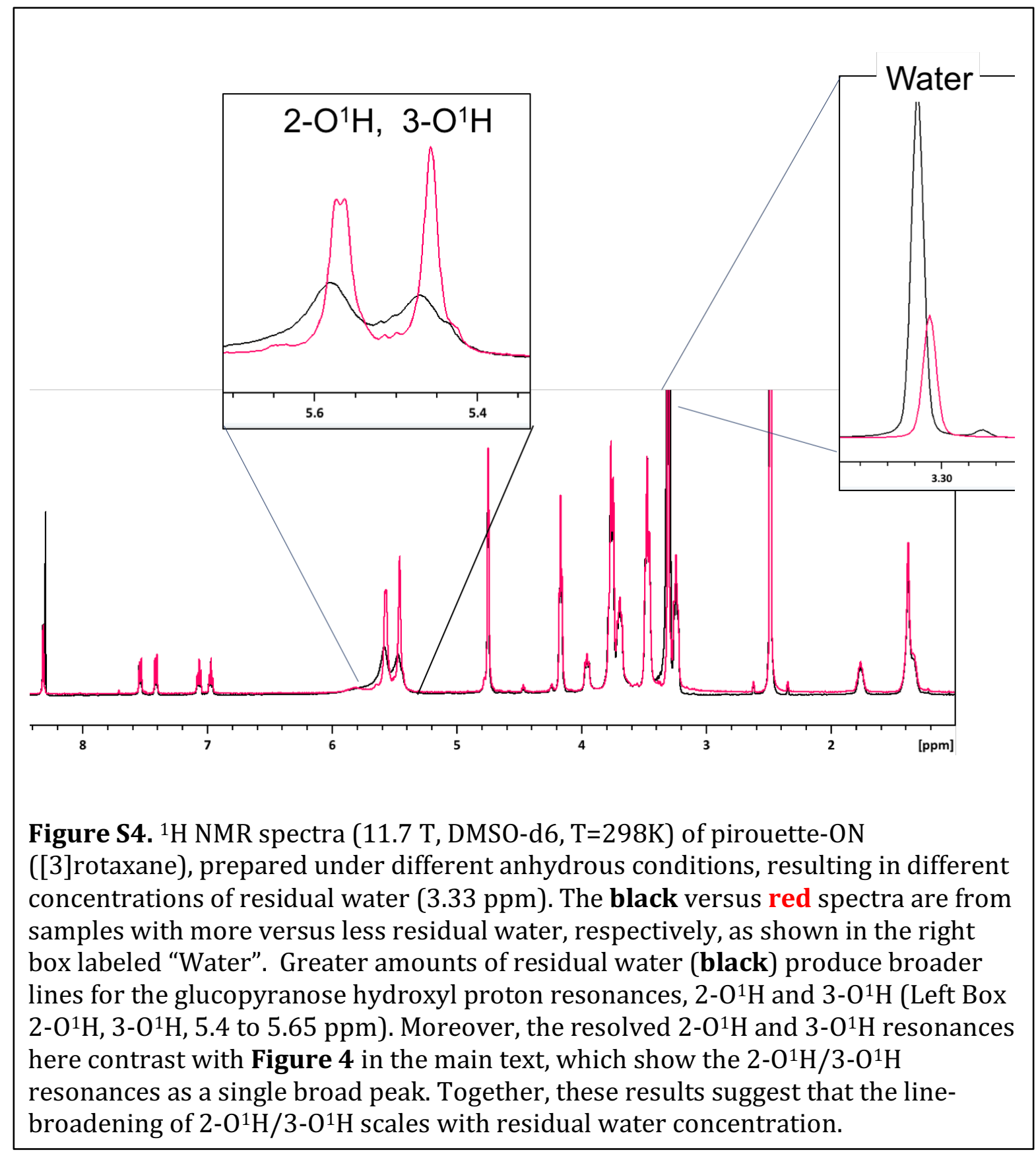




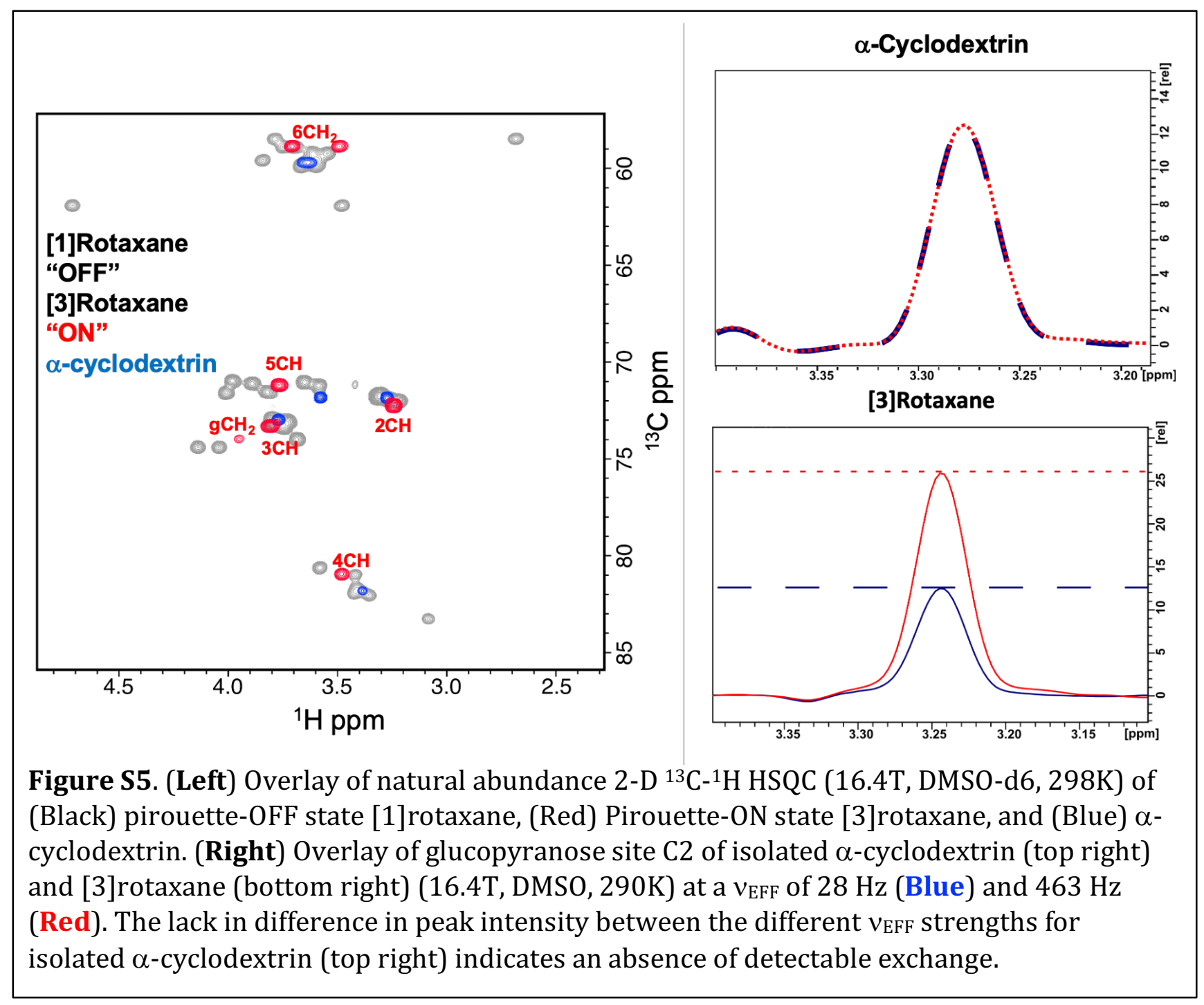




\section{E. Supporting Information References}

1. Zhang, Q. W.; Zajicek, J.; Smith, B. D., Cyclodextrin Rotaxane with Switchable Pirouetting. Org Lett 2018, 20 (7), 2096-2099.

2. Ammann, C.; Meier, P.; Merbach, A. E., A Simple Multinuclear NMR Thermometer. Journal of Magnetic Resonance 1982, 46, 319-321.

3. Rance, M.; Sorensen, O. W.; Bodenhausen, G.; Wagner, G.; Ernst, R. R.; Wuthrich, $\mathrm{K}$., Improved spectral resolution in COSY H-1-NMR spectra of proteins via double quantum filtering. Biochemical and Biophysical Research Communications 1983, 117 (2), 479-485.

4. Shaka, A. J.; Lee, C. J.; Pines, A., Iterative schemes for bilinear operators; application to spin decoupling. Journal of Magnetic Resonance 1988, 77 (2), 274-293.

5. Fulton, D. B.; Ni, F., ROESY with Water Flip Back for High-Field NMR of Biomolecules. 1997, 129 (1), 93-97.

6. Jeener, J.; Meier, B. H.; Bachmann, P.; Ernst, R. R., Investigatoin of exchange processes by two-dimensional NMR spectroscopy. J. Chem. Phys. 1979, 71 (11), 4546-4553.

7. Macura, S. I.; Ernst, R. R., Elucidation of cross relaxation in liquids by two-dimensional N.M.R. spectroscopy. Mol. Phys. 1980, 41 (1), 95-117.

8. $\quad$ Palmer, A. G.; Cavanagh, J.; Wright, P. E.; Rance, M., Sensitivity improvement in proton-detected two-dimensional heteronuclear correlation NMR spectroscopy. 1991, 93 (1), $151-170$.

9. Kay, L. E., NMR studies of protein structure and dynamics. J Magn Reson 2005, 173 (2), 193-207.

10. Bodenhausen, G.; Ruben, D. J., Natural abundance nitrogen-15 NMR by enhanced heteronuclear spectroscopy. 1980, 69 (1), 185-189.

11. Kover, K. E.; Hruby, V. J.; Uhrin, D., Sensitivity- and gradient-enhanced heteronuclear coupled/decoupled HSQC-TOCSY experiments for measuring long-range heteronuclear coupling constants. Journal of Magnetic Resonance 1997, 129 (2), 125-129.

12. Claridge, T. D. W., Chapter 3: Practical Aspect of High-Resolution NMR. In High Resolution NMR Techniques in Organic Chemistry, Pergamon: 1999; p 76.

13. Nirmala, N. R.; Wagner, G., Measurement of $13 \mathrm{C}$ relaxation times in proteins by twodimensional heteronuclear 1H-13C correlation spectroscopy. J. Am. Chem. Soc. 1988, 110 (22), 7557-7558.

14. Palmer, A. G.; Rance, M.; Wright, P. E., Intramolecular motions of a zinc finger DNAbinding domain from Xfin characterized by proton-detected natural abundance carbon-13 heteronuclear NMR spectroscopy. J. Am. Chem. Soc. 1991, 113 (12), 4371-4380.

15. McCain, D. C.; Markley, J. L., Water permeability of chloroplast envelope membranes. In vivo measurement by saturation-transfer NMR. Febs Letters 1985, 183 (2), 353-358.

16. Farrar, T. C.; Adams, B. R.; Grey, G. C.; Quintero-Arcaya, R. A.; Zuo, Q., 13C Differential Line Broadening and the Experimental Measurement of the Absolute Signs of the One-Bond Carbon-Hydrogen Spin-Coupling Constants in Phenylacetylene. J. Am. Chem. Soc. 1986, $108,8190-8193$.

17. Boyd, J.; Hommel, U.; Campbell, I. D., Influence of cross-correlation between dipolar and anisotropic chemical shift relaxation mechanisms upon longitudinal relaxation rates of $15 \mathrm{~N}$ in macromolecules. Chem. Phys. Lett. 1990, (175), 477-482. 
18. Palmer III, A. G.; Skelton, N. J.; Chazin, W.; Wright, P. E.; Rance, M., Suppression of the effects of cross-correlation between dipolar and anisotropic chemical shift relaxation mechanisms in the measurement of spin-spin relaxation rates. Mol. Phys. 1992, 75 (3), 699-711. 19. Kay, L. E.; Nicholson, L. K.; Delaglio, F.; Bax, A.; Torchia, D. A., Pulse Sequences for Removal of the Effects of Cross Correlation between Dipolar and Chemical-Shift Anisotropy Relaxation Mechanisms on the Measurement of Heteronuclear TI and T2 Values in Proteins. $J$. Magn. Reson. 1992, 97, 359-375.

20. Press, W.; Teukolsky, S.; Vetterling, W.; Flannery, B., Numerical recipes in C: The Art of Scientific Computing. Cambridge University Press: Cambridge, UK, 1992; pp 1-994.

21. Carr, H. Y.; Purcell, E. M., Effects of Diffusion on Free Precession in Nuclear Magnetic Resonance Experiments. Phys Rev 1954, 94 (3), 630-638.

22. Meiboom, S.; Gill, D., Modified Spin-Echo Method for Measuring Nuclear Relaxation Times. Review of Scientific Instruments 1958, 29 (8), 688-691.

23. Loria, J. P.; Rance, M.; Palmer, A. G., A Relaxation-Compensated Carr-Purcell-Meiboom-Gill Sequence for Characterizing Chemical Exchange by NMR Spectroscopy. J. Am. Chem. Soc. 1999, 121 (10), 2331-2332.

24. Mulder, F. A. A.; Skrynnikov, N. R.; Hon, B.; Dahlquist, F. W.; Kay, L. E., Measurement of slow (mu s-ms) time scale dynamics in protein side chains by $\mathrm{N}-15$ relaxation dispersion NMR spectroscopy: Application to Asn and Gln residues in a cavity mutant of T4 lysozyme. J. Am. Chem. Soc. 2001, 123 (5), 967-975.

25. Millet; Loria, J. P.; Kroenke, C. D.; Pons, M.; Palmer, A. G., The Static Magnetic Field Dependence of Chemical Exchange Linebroadening Defines the NMR Chemical Shift Time Scale. J Am Chem Soc 2000, 122 (12), 2867-2877.

26. Loria, J. P.; Berlow, Rebecca B.; Watt, Eric D., Characterization of Enzyme Motions by Solution NMR Relaxation Dispersion. Accounts of Chemical Research 2008, 41 (2), 214-221.

27. Mulder, F. A.; Mittermaier, A.; Hon, B.; Dahlquist, F. W.; Kay, L. E., Studying excited states of proteins by NMR spectroscopy. Nat Struct Biol 2001, 8 (11), 932-5.

28. Carver, J. P.; Richards, R. E., A general two-site solution for the chemical exchange produced dependence of T2 upon the carr-Purcell pulse separation. 1972, 6 (1), 89-105.

29. Bevington, P. R., Data Reduction and Error Analysis for the Physical Sciences. McGraw-Hill Book Company: 1969.

30. Deverell, C.; Morgan, R. E.; Strange, J. H., Studies of Chemical Exchange by Nuclear Magnetic Relaxation in Rotating Frame. Mol Phys 1970, 18 (4), 553-\&.

31. Blackledge, M. J.; Bruschweiler, R.; Griesinger, C.; Schmidt, J. M.; Xu, P.; Ernst, R. R., Conformational Backbone Dynamics of the Cyclic Decapeptide Antamanide - Application of a New Multiconformational Search Algorithm-Based on Nmr Data. Biochemistry-Us 1993, 32 (41), 10960-10974.

32. Griesinger, C.; Ernst, R. R., Frequency Offset Effects and Their Elimination in NMR Rotating-Frame Cross-Relaxation Spectroscopy. J. Magn. Reson. 1987, 75, 261-271.

33. Dalvit, C.; Hommel, U., New Pulsed-Field Gradient Nmr Experiments for the Detection of Bound Water in Proteins. Journal of Biomolecular Nmr 1995, 5 (3), 306-310.

34. Geen, H.; Freeman, R., Band-Selective Radiofrequency Pulses. J. Magn. Reson. 1991, 93, 93-141.

35. Trott, O.; Palmer, A. G., R1 $\rho$ Relaxation outside of the Fast-Exchange Limit. 2002, 154 (1), 157-160. 
36. Morris, K. F.; Johnson, C. S., Diffusion-ordered two-dimensional nuclear magnetic resonance spectroscopy. Journal of the American Chemical Society 1992, 114 (8), 3139-3141. 37. Colbourne, A. A.; Morris, G. A.; Nilsson, M., Local Covariance Order DiffusionOrdered Spectroscopy: A Powerful Tool for Mixture Analysis. J. Am. Chem. Soc. 2011, 133 (20), 7640-7643.

38. Nilsson, M., The DOSY Toolbox: A new tool for processing PFG NMR diffusion data. $J$ Magn Reson 2009, 200 (2), 296-302. 